\title{
PENGARUH KINERJA TEKNOLOGI INFORMASI DAN INOVASI TEKNOLOGI TERHADAP KEUNGGULAN DAYA SAING BERKELANJUTAN (STUDI KASUS PT TOTAL BANGUN PERSADA, TBK)
}

\author{
Anwar P. Boima Silalahi \\ Program Studi Magister Manajemen Universitas Tarumanagara \\ anwar.silalahi@gmail.com \\ Nurahma Tresani \\ Program Studi Magister Manajemen Universitas Tarumanagara \\ Masuk : 06-06-2020, revisi : 26-06-2020 diterima untuk diterbitkan : 26-06-2020
}

\begin{abstract}
This research aims to analyze effect of Information Technology Performance and Technology Innovation on Sustainable Competitive Advantage, case study Construction Company PT Total Bangun Persada, Tbk. This study uses data collected by a survey for active working employee in the company. Sample taken for this research are 200 employees. Data sent by respondent are goodness of fit analyzed using confirmatory factor analysis of structural equation modelling (SEM AMOS) to the research model based on theoretical mindset. The result shows that simultaneously IT Performance and Technology Innovation have positive influence on Sustainable Competitive Advantage. It also shows that Business Resources and Technology Resources have significant influence on IT Performance; Differentiation has positive influence on Technology Innovation. While Organizational Culture has no significant influence on IT Performance; Special Asset Complexity has no significant influence on Technology Innovation.

Keywords: Sustainable Competitive Advantage, IT Performance, Organizational Culture, Business Resource, Technology Resource, Technology innovation, Special Asset Complexity, Differentiation
\end{abstract}

\begin{abstract}
Abstrak: Penelitian ini bertujuan untuk menganalisis pengaruh Kinerja Teknologi Informasi dan Teknologi Inovasi terhadap Keunggulan Daya Saing Berkelanjutan dengan kasus Perusahaan Konstruksi PT Total Bangun Persada, Tbk. Penelitian ini menggunakan data yang dikumpulkan melalui survei untuk karyawan yang masih bekerja dan aktif di perusahaan. Sampel yang diambil untuk penelitian ini adalah 200 karyawan. Data yang dikirim oleh responden adalah analisis goodness of fit menggunakan analisis faktor konfirmatori pemodelan persamaan struktural (SEM AMOS) ke model penelitian berdasarkan pola pikir teoritis. Hasil penelitian menunjukkan bahwa secara simultan Kinerja TI dan Inovasi Teknologi, berpengaruh positif terhadap Keunggulan Daya Saing Berkelanjutan. Selain itu Sumber Daya Bisnis dan Sumber Daya Teknologi berpengaruh positif terhadap Kinerja TI; Diferensiasi berpengaruh positif terhadap Inovasi Teknologi. Sedangkan Budaya Organisasi tidak memiliki pengaruh terhadap Kinerja TI, dan Kompleksitas Aset Khusus tidak memiliki pengaruh terhadap Inovasi Teknologi.
\end{abstract}

Kata Kunci: Keunggulan Daya Saing Berkelanjutan, Kinerja TI, Budaya Organisasi, Sumber Daya Bisnis, Sumber Daya Teknologi, Inovasi teknologi, Kompleksitas Aset Khusus, Diferensiasi.

\section{PENDAHULUAN}

Persaingan dalam industri jasa konstruksi memang sangat ketat dan hal ini juga dirasakan oleh PT Total Bangun Persada Tbk dalam menjalankan bisnisnya di Indonesia. Teknologi berkembang dengan cepat, sehingga sulit untuk dikelola oleh organisasi sejajar dengan 
teknologi terbaru (Devandran, John Manson, 2018:1). Keunggulan daya saing berkelanjutan merupakan arah strategi perusahaan yang bukan merupakan tujuan akhir, tetapi merupakan suatu stratregi untuk mencapai tujuan perusahaan. Pencapaian keunggulan daya saing berkelanjutan dilakukan dengan melakukan diferensiasi melalui inovasi teknologi (Nur Farih hakim, 2006:8). Oleh karena itu, inovasi teknologi diduga sebagai salah satu faktor yang mempengaruhi keunggulan bersaing perusahaan jasa konstruksi.

Perusahaan dapat menggunakan teknologi untuk mempertahankan dan menciptakan keunggulan daya saing, baik dengan biaya atau diferensiasi. (Devandran, John Manson, 2018:1). Konsep strategi teknologi dan inovasi teknologi adalah menjadi penting dalam merumuskan strategi business (Carlos roberto, 2014:.22).

\section{Tujuan Penelitian}

Tujuan penelitian ini adalah:

a. Menganalisis pengaruh kinerja teknologi informasi terhadap keunggulan daya saing berkelanjutan

b. Menganalisis pengaruh budaya organisasi terhadap kinerja teknologi informasi

c. Menganalisis pengaruh sumber daya daya bisnis terhadap kinerja teknologi informasi

d. Menganalisis pengaruh inovasi teknologi terhadap keunggulan daya saing berkelanjutan

e. Menganalisis pengaruh kompleksitas aset khusus terhadap inovasi teknologi

f. Menganalisis pengaruh diferensiasi terhadap inovasi teknologi.

\section{LANDASAN TEORI}

\section{Keunggulan Daya Saing Berkelanjutan}

Keunggulan daya saing adalah keunggulan yang dimiliki perusahaan (a) dibandingkan pesaingnya, (b) berkembang menggunakan sumber dayanya, dan (c) gunakan untuk mendorong kinerja yang unggul (Gupta, tan, Ee, Phan, 2018:4). Hasil dari keunggulan daya saing perusahaan lebih mudah untuk dinilai daripada sumber keunggulannya. Suatu perusahaan dapat dipandang memiliki keunggulan daya saing terhadap pesaingnya ketika dapat menciptakan nilai ekonomi yang lebih, dan keunggulan daya saing yang berkelanjutan serta keunggulan yang bertahan lama (Benjamin maury, 2017:7)

\section{Teknologi Informasi}

Sistem Informasi merupakan sistem manusia atau mesin yang terpadu untuk menyajikan informasi, guna mendukung fungsi operasi manajemen dan pengambilan keputusan dalam sebuah organisasi (Setyaningsih, 2010:64). Kemajuan teknologi informasi ke zaman modern, mengurangi kebutuhan akan tenaga kerja manual dan bentuk pemborosan (Waste) lainnya (Devandran, John Manson, 2018:40). Teknologi merupakan salah satu faktor yang mempengaruhi kesuksesan produk baru, dimana dengan menggunakan teknologi yang canggih, perusahaan dapat, menciptakan produknya menjadi lebih baik atau lebih inovatif. Keunggulan diferensiasi produk memiliki pengaruh yang sangat besar, terutama pada perusahaan yang berteknologi tinggi, dimana hal ini ditunjukkan oleh beberapa keunggulan yang berbeda (Heri Setiawan, 2012:13)

\section{Budaya Organisasi}

Budaya Organisasi merupakan sesuatu hal yang sifatnya mendasar, yang berisi keyakinan, nilai-nilai inti bersama, sesuatu yang menjadi karakteristik inti, yang diyakini dan dijalankan bersama-sama oleh semua anggota organisasi (Dian, 2014:194). Budaya yang kuat adalah aset vital bagi organisasi untuk mendorong partisipasi karyawan dalam ber inovasi (John D Pennington, 2017:5). Perusahaan perlu menyadari bahwa budaya organisasi penting dalam penciptaan keunggulan daya saing konstruksi. Kajian-kajian terhadap keunggulan daya saing berkelanjutan berhasil mengungkap bahwa budaya organisasi adalah salah satu sumber daya yang penting dalam menciptakan keunggulan daya saing yang berkelanjutan bagi perusahaan. (Adi winata, 2015:82) 


\section{Sumber Daya Bisnis}

Sumber daya bisnis yang digunakan untuk meningkatkan kinerja teknologi informasi adalah pelatihan dan pengembangan. Hal tersebut bertujuan untuk mengukur kinerja implementasi teknologi informasi dalam sumber daya bisnis. Salah satu alternatif dalam pengembangan daya saing sistem teknologi informasi termasuk unit-unit di dalamnya adalah melalui benchmarking (Nur farih hakim, 2006:15). Benchmarking merupakan standardisasi dan pengukuran kinerja. Jika kinerja terukur, maka perkembangannya dan dampaknya terhadap Kinerja teknologi informasi terpantau.

\section{Sumber Daya Teknologi}

Globalisasi telah membawa perubahan teknologi yang cepat, yang memunculkan inovasi cara berbisnis. Teknologi baru terus diperkenalkan ke pasar, yang menyediakan metode yang lebih efisien bagi organisasi untuk meningkatkan proses bisnis (Devandran, John Manson, 2018:40). Untuk membangun dan mendukung infastruktur teknologi informasi, perlu dilakukan pengaturan antara unit-unit teknologi informasi yang ada dan membangun standar untuk pelaksanaannya agar penerapan Teknologi Informasi di dalam manajemen perusahaan menjadi efisien (Nur farih hakim, 2006:16)

\section{Inovasi teknologi}

Inovasi adalah keberhasilan sosial dan ekonomi berkat diperkenalkannya atau ditemukannya cara-cara baru atau kombinasi baru dari cara-cara lama dalam mentransformasi input menjadi output sedemikian rupa sehingga berhasil menciptakan perubahan besar atau perubahan drastis dalam hubungan antara nilai guna atau nilai manfaat. Mario Coccia (2016) menunjukkan bahwa evolusi teknologi dapat juga disebabkan oleh parasitisme teknologi dan interaksi simbiosis antara teknologi. Inovasi juga karena pembelajaran organisasi, yang merupakan proses strategis untuk keunggulan daya saing perusahaan. Selain itu, manajer dengan kepemimpinan strategis memainkan peran penting untuk proses inovasi perusahaan karena mereka menginspirasi orang lain dengan visi mereka, menciptakan kegembiraan dalam kelompok dan memberikan insentif untuk mencapai tujuan dalam lingkungan yang daya saing (Mario Coccia, 2016:8)

\section{Kompleksitas Aset Khusus}

Aset-aset khusus (special assets) pada inovasi berdampak pada sulitnya inovasi tesebut untuk ditiru. Ketika inovasi dikomersilkan, dibutuhkan aset-aset yang dibuat khusus (specialized assets) dalam pemasaran dan dalam produksi. Kemampuan inovasi untuk ditiru akan dihalangi oleh derajad kerumitan (kompleksitas) dan jumlah aset khusus yang dibutuhkan (Nur farih hakim, 2006:19).

\section{Diferensiasi}

Diferensiasi adalah tindakan merancang sekumpulan perbedaan yang berarti untuk membedakan penawaran perusahaan dengan penawaran pesaing. Sebuah perusahaan dapat membedakan dirinya dengan berbagai cara, seperti menawarkan fitur inovatif, meluncurkan promosi yang efektif, memberikan layanan yang unggul, mengembangkan nama merek yang kuat, dan sebagainya. Bharadwaj et al. (1993) dalam kutipan Nur farih hakim (2006) berpendapat bahwa tiap inovasi berkekuatan menjual (selling point) cenderung diduplikasi dengan cepat oleh pesaing. Karena itu diperlukan diferensiasi yang salah satu keberhasilannya adalah sulitnya inovasi tersebut untuk diduplikasi oleh pesaing.

\section{METODOLOGI PENELITIAN}

Penelitian ini menggunakan analisis data yang disesuaikan dengan pola penelitian dan variabel yang diteliti. Model yang digunakan dalam penelitian ini adalah model kausalitas dan untuk menguji hipotesis yang diajukan dalam penelitian ini maka teknik analisis yang digunakan adalah SEM (Stuctural Equation Modelling) yang dioperasikan melalui program AMOS. Penelitian ini dilakukan kepada para karyawan perusahaan jasa konstruksi Indonesia berskala besar yaitu PT Total Bangun Persada Tbk berdasarkan hasil penelitian yang dilakukan 
terhadap 200 responden yaitu Para karyawa di PT Total Bangun Persada Tbk yang bekerja di lingkungan proyek dan departemen.

\section{ANALISIS DATA DENGAN SEM AMOS}

Setelah dilakukan pengolahan data secara umum, maka dilanjutkan dengan analisis menggunakan software SEM AMOS yang bertujuan untuk mengidentifikasi pengaruh kinerja teknologi informasi (IT performance) terhadap keunggulan daya saing berkelanjutan, pengaruh budaya organisasi terhadap kinerja teknologi informasi (IT performance), pengaruh technology resource terhadap kinerja teknologi informasi (IT performance), pengaruh inovasi teknologi terhadap keunggulan daya saing berkelanjutan, pengaruh kompleksitas aset khusus terhadap inovasi teknologi, dan pengaruh diferensiasi terhadap inovasi teknologi

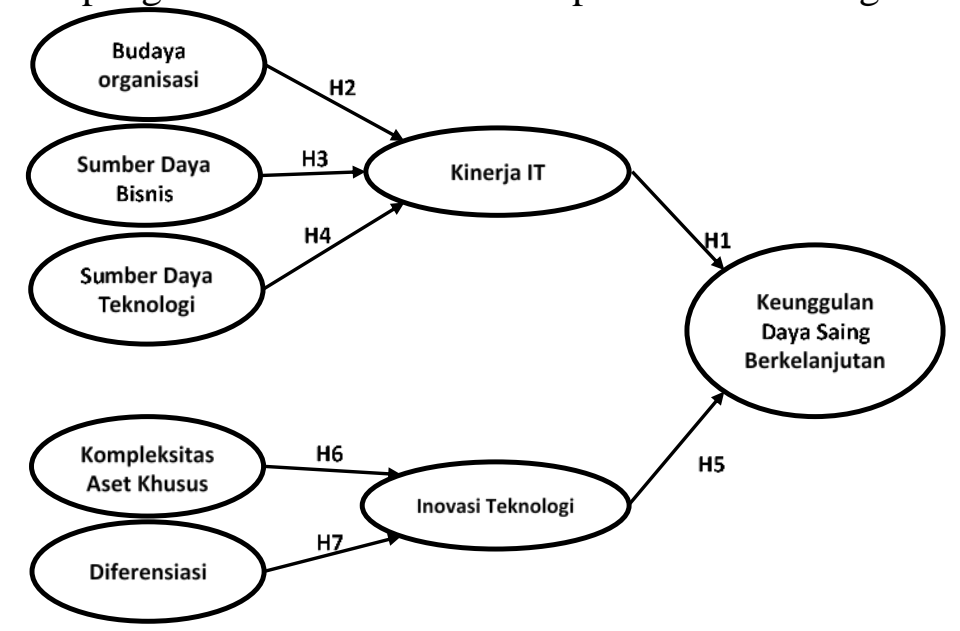

Gambar 1

Kerangka Penelitian

Tabel 1

Hasil goodness of fit Setelah Modifikasi

\begin{tabular}{|l|l|l|l|l|}
\hline No. & Goodness of Fit Index & Cut off Value & Hasil Analisis & Evaluasi Model \\
\hline 1 & X2 - Chi Square & Sekecil mungkin & 117.008 & Good fit \\
\hline 2 & Probabilitas & $\geq 0.05$ & 0.118 & Good fit \\
\hline 3 & CMIN/DF & $\leq 2.0$ & 1.170 & Good fit \\
\hline 4 & RMSEA & $\leq 0.08$ & 0.029 & Good fit \\
\hline 5 & GFI & Mendekati 1 & 0.938 & Good fit \\
\hline 6 & AGFI & Mendekati 1 & 0.905 & Good fit \\
\hline 8 & TLI & Mendekati 1 & 0.996 & Good fit \\
\hline 9 & CFI & Mendekati 1 & 0.997 & Good fit \\
\hline
\end{tabular}

Sumber: Pengolahan Data Penelitian AMOS

Tabel 1 Menunjukkan bahwa model yang direncanakan fit secara baik, karena setelah diuji kecocokannya nilai CMIN/ DF, GFI, AGFI, RMSEA, TLI dan CFI hasilnya baik. Sehingga dapat diambil kesimpulan hasil uji modifikasi lebih baik dibandingkan model awal.

\section{PENGUJIAN HIPOTESIS}

Setelah tahap-tahap pengujian terhadap kesesuaian model dan normalitas data dilakukan, maka langkah selanjutnya adalah pengujian hipotesis penelitian yang diajukan. Pengujian hipotesis ini didasarkan atas pengolahan data penelitian dengan menggunakan analisis SEM, dengan cara menganalisis nilai regresi yang ditampilkan pada Tabel (Regression Weigts Analisis Structiural Equation Modeling). Pengujian hipotesis ini adalah dengan menggunakan nilai Probability ( $P$ Value) hasil olah data, dibandingkan dengan batasan statistik yang diisyratkan, yaitu dibawah 0.05 untuk nilai $\mathrm{P}$ Value. Untuk menguji hipotesis mengenai kausalitas yang dikembangkan dalam model penelitian ini, perlu diuji hipotesis nol yang menyatakan bahwa koefisien regresi antar hubungan adalah sama dengan nol melalui uji-t yang 
lazim digunakan dalam model- model regresi. Dalam output dari SEM uji kausalitas ini dilakukan dengan membaca nilai $C R$ (Critical Ratio) yang identik dengan uji-t. Hasil pengujian tertuang pada Tabel 2 .

Tabel 2

Hasil Output SEM

\begin{tabular}{|c|c|c|c|c|c|c|c|c|}
\hline Hipotesis & & & & & Estimate & S.E. & C.R. & $\mathbf{P}$ \\
\hline H1 & $\begin{array}{ll}\text { Keunggulan } & \text { Day } \\
\text { Berkelanjuan } & \\
\end{array}$ & Saing & $<--$ & Kinerja TI & 0.315 & 0.119 & 2.648 & 0.008 \\
\hline H2 & Kinerja TI & & $<--$ & Budaya organisasi & 0.214 & 0.154 & 1.388 & 0.165 \\
\hline H3 & Kinerja TI & & $<--$ & Sumber Daya Bisnis & 0.416 & 0.13 & 3.209 & 0.001 \\
\hline H4 & Kinerja TI & & $<--$ & Sumber Daya Teknologi & 0.309 & 0.148 & 2.092 & 0.036 \\
\hline H5 & $\begin{array}{ll}\text { Keunggulan } & \text { Day } \\
\text { Berkelanjutan } & \\
\end{array}$ & Saing & $<--$ & Inovasi Teknologi & 0.626 & 0.135 & 4.65 & $* * *$ \\
\hline H6 & Inovasi Teknologi & & $<---$ & $\begin{array}{ll}\begin{array}{l}\text { Kompleksitas } \\
\text { Khusus }\end{array} & \text { Aset } \\
\end{array}$ & 0.08 & 0.063 & 1.27 & 0.204 \\
\hline H7 & Inovasi Teknologi & & $<--$ & Diferensiasi & 0.785 & 0.059 & 13.281 & $* * *$ \\
\hline
\end{tabular}

\section{KESIMPULAN}

Berdasarkan hasil analisis data tersebut maka dapat disimpulkan sebagai berikut:

1. Kinerja TI berpengaruh positif dan signifikan terhadap Keunggulan Daya Saing Berkelanjuan. Hal ini di tunjukkan dengan nilai probabilitas sebesar 0.008 yang berada di bawah alfa sebesar 5\% $(0,05)$. Dengan demikian hipotesis $\mathrm{H}_{1}$ terbukti dalam penelitian ini.

2. Budaya organisasi tidak berpengaruh signifikan terhadap Kinerja TI. Hal ini di tunjukkan dengan nilai probabilitas sebesar 0.165 yang berada diatas sebesar $5 \%(0,05)$. Dengan demikian hipotesis $\mathrm{H}_{2}$ tidak terbukti dalam penelitian ini.

3. Sumber Daya Bisnis berpengaruh positif dan signifikan terhadap Kinerja TI. Hal ini di tunjukkan dengan nilai probabilitas sebesar 0.001 yang berada di bawah alfa sebesar $5 \%$ $(0,05)$. Dengan demikian hipotesis $\mathrm{H}_{3}$ terbukti dalam penelitian ini.

4. Sumber Daya Teknologi berpengaruh positif dan signifikan terhadap Kinerja TI. Hal ini di tunjukkan dengan nilai probabilitas sebesar 0.036 yang berada di bawah alfa sebesar $5 \%(0,05)$. Dengan demikian hipotesis $\mathrm{H}_{4}$ terbukti dalam penelitian ini.

5. Inovasi Teknologi berpengaruh positif dan signifikan terhadap Keunggulan Daya Saing Berkelanjuan. Hal ini di tunjukkan dengan nilai probabilitas sebesar 0.000 yang berada di bawah alfa sebesar 5\% $(0,05)$. Dengan demikian hipotesis $\mathrm{H}_{5}$ terbukti dalam penelitian ini.

6. Kompleksitas Aset Khusus tidak berpengaruh signifikan terhadap Inovasi Teknologi. Hal ini di tunjukkan dengan nilai probabilitas sebesar 0.204 yang berada diatas sebesar 5\% $(0,05)$. Dengan demikian hipotesis $\mathrm{H}_{6}$ tidak terbukti dalam penelitian ini.

7. Diferensiasi berpengaruh positif dan signifikan terhadap Inovasi Teknologi. Hal ini di tunjukkan dengan nilai probabilitas sebesar 0.000 yang berada di bawah alfa sebesar $5 \%$ $(0,05)$. Dengan demikian hipotesis $\mathrm{H}_{7}$ terbukti dalam penelitian ini

\section{DAFTAR PUSTAKA}

Bharadwaj, S. G., Varadarajan, P. R., \& Fahy, J. (1993). Sustainable competitive advantage in service industries: A conceptual model and research proposition. Journal of Marketing, 57(4), 83, 17 pgs.

Coccia, M. (2016). Sources of technological innovation: Radical and incremental innovation problem-driven to support competitive advantage of firms. Arizona State University \& CNR - National Research Council of Italy, Tempe, AZ 85287, USA

Gupta, T. \& Ee, P. (2018). Resource-based view of information systems: sustainable and transient competitive advantage perspectives. Australasian Journal of Information, 22, Research Note. 
Hakim, N. F. (2006). Strategi Peningkatan Keunggulan Bersaing Berkelanjutan Melalui Kinerja Teknologi Informasi dan Inovasi Teknologi. Semarang: Universitas Diponegoro.

Indiyati, D. (2014). Pengaruh Budaya organisasi dan manajemen pengetahuan terhadap keunggulan bersaing. Sosiohumaniora, 16(2).

Maury, B. (2017). Sustainable competitive advantage and profitability persistence: Sources versus outcomes for assessing advantage. Journal of Business Research, forthcoming.

Nainaar, D. \& Masson, J. (2018). An investigation into technology management to create sustainable competitive advantage. European Journal of Engineering and Technology, 2(2).

Pennington, J. D. (2017). Developing A Strong Organizational Culture To Create A Sustainable Competitive Advantage: A Case Study Of Winning College Football Coaches, A Dissertation Presented in Partial Fulfillment Of the Requirements for the Degree Doctor of Philosophy. Capella University

Roberto, C. (2014). Directions for supply chain strategic coordination discussion and proposal. Journal of Management Research, 6(3).

Setiawan, H. (2012). Pengaruh orientasi pasar, orientasi teknologi, dan inovasi produk terhadap keunggulan bersaing usaha songket skala kecil di kota Palembang. Jurnal Orasi Bisnis, Edisi ke-VIII.

Setyaningsih. (2010). Pengaruh Teknologi Informasi dalam Perkembangan Bisnis. Surakarta: Fakultas Ekonomi Universitas Slamet Riyadi

Winata, A., Windia, W., \& Suartana, I. W. (2015). Membangun strategi operasi melalui budaya organisasi berbasis Tri Hita Karana untuk mencapai keunggulan bersaing berkelanjutan, Jurnal Manajemen Agribisnis, 3(2). 